University of Nebraska - Lincoln

DigitalCommons@University of Nebraska - Lincoln

\title{
Performance of Larval Florida Pompano Fed Nauplii of the Calanoid Copepod Pseudodiaptomus pelagicus
}

\author{
Eric J. Cassiano \\ University of Florida \\ Cortney L. Ohs \\ University of Florida, cohs@ufl.edu \\ Charles R. Weirich \\ Aqua Green, LLC \\ Nancy E. Breen \\ Roger Williams University \\ Andrew L. Rhyne \\ Roger Williams University
}

Follow this and additional works at: https://digitalcommons.unl.edu/usdaarsfacpub

Part of the Agricultural Science Commons

\footnotetext{
Cassiano, Eric J.; Ohs, Cortney L.; Weirich, Charles R.; Breen, Nancy E.; and Rhyne, Andrew L., "Performance of Larval Florida Pompano Fed Nauplii of the Calanoid Copepod Pseudodiaptomus pelagicus" (2011). Publications from USDA-ARS / UNL Faculty. 605.

https://digitalcommons.unl.edu/usdaarsfacpub/605
}

This Article is brought to you for free and open access by the U.S. Department of Agriculture: Agricultural Research Service, Lincoln, Nebraska at DigitalCommons@University of Nebraska - Lincoln. It has been accepted for inclusion in Publications from USDA-ARS / UNL Faculty by an authorized administrator of DigitalCommons@University of Nebraska - Lincoln. 


\title{
Performance of Larval Florida Pompano Fed Nauplii of the Calanoid Copepod Pseudodiaptomus pelagicus
}

\author{
Eric J. Cassiano and Cortney L. Ohs* \\ Program in Fisheries and Aquatic Sciences, School of Forest Resources and Conservation, \\ Institute of Food and Agricultural Sciences, University of Florida, 7922 Northwest 71 st Street, \\ Gainesville, Florida 32653, USA; and Indian River Research and Education Center, \\ Institute of Food and Agricultural Sciences, University of Florida, 2199 South Rock Road, \\ Fort Pierce, Florida 34945, USA
}

Charles R. Weirich ${ }^{1}$

U.S. Department of Agriculture, Agricultural Research Service, 5600 U.S. Highway 1 North, Fort Pierce, Florida 34946, USA

\section{Nancy E. Breen}

Department of Chemistry, Roger Williams University, One Old Ferry Road, Bristol, Rhode Island 02809, USA

\author{
Andrew L. Rhyne \\ Department of Biology and Marine Biology, Roger Williams University, One Old Ferry Road, Bristol, \\ Rhode Island 02809, USA; and New England Aquarium, Edgerton Research Laboratory, \\ One Central Wharf, Boston, Massachusetts 02110, USA
}

\begin{abstract}
The Florida pompano Trachinotus carolinus is a highly prized marine fish species, the larviculture of which currently includes the feeding of live rotifers and nauplii of brine shrimp Artemia spp. However, no previous studies have evaluated the feeding of copepod nauplii. In this study, the growth and survival of Florida pompano larvae fed nauplii of the calanoid copepod Pseudodiaptomus pelagicus were compared with those of larvae fed the standard reference diet of enriched rotifers Brachionus plicatilis. Experiments were conducted during the first 7-9 d posthatch (DPH), a period preceding the provision of Artemia nauplii. Treatments included feeding only copepod nauplii during the first day, the first three days, and on all days, as well as copepod nauplii mixed with rotifers during the entire experiment. In addition, the dietary effects on larval fatty acid composition were examined. Feeding copepod nauplii at a density of 2.0-3.5 nauplii/mL during the first day or the first three days of feeding had advantages over feeding only rotifers. However, after approximately $3 \mathrm{DPH}$, increased quantities of nauplii were needed to provide sufficient nutrients for growth. This was demonstrated in larvae fed copepod nauplii for the entire trial, for which survival was significantly higher than for the other treatments but for which growth was significantly reduced. Larvae fed a mixture of rotifers and nauplii for the entire trial had survival similar to that of larvae fed only rotifers $(\sim 40 \%)$; however, growth was greater in larvae fed the mixed diet, suggesting that there is a nutritional advantage to including copepods in the diet. Fatty acid analyses revealed that increased levels of docosahexaenoic acid were associated with larvae fed copepods, which probably contributed to the observed higher survival and growth. These results indicate that there are multiple benefits to feeding copepods to Florida pompano larvae.
\end{abstract}

*Corresponding author: cohs@ufl.edu

${ }^{1}$ Present address: Aqua Green, LLC, 60 Chalet Drive, Perkinston, Mississippi 39573, USA.

Received June 6, 2010; accepted August 10, 2010 
The development of marine fish production methods is critical to the advancement of the food, bait, and ornamental aquaculture industries. Currently, only a limited number of species are being produced, and those with variable success (Lavens and Sorgeloos 1999; Stottrup and McEvoy 2003; FAO 2008). One of the major impediments to increasing production of currently grown species and success rearing candidate species is the lack of an appropriate live feed during the first feeding phase of the larval cycle (Lee et al. 2005). This period is extremely difficult for marine larval fish culturists. A live feed with an adequate nutritional composition, particularly the highly unsaturated fatty acids (HUFAs) docosahexaenoic acid (DHA; 22:6[n-3 $]^{1}$ ), eicosapentaenoic acid (EPA; 20:5[n-3]), and arachidonic acid (ARA; 20:4[n-6]), as reported by Sargent et al. (1999a, 1999b), within a suitable size range (McKinnon et al. 2003; Chesney 2005) that stimulates a feeding response (Stottrup and Norsker 1997) is necessary for expanding the number of marine fish species cultured.

Establishing larviculture protocols that include copepods may be necessary to optimize production of marine fish species. Copepods are the predominant prey item for a vast majority of wild marine fish larvae (Hunter 1981; Leis 1991; Østergaard et al. 2005; Samprey et al. 2007). Furthermore, copepods contain the appropriate HUFA composition required for the growth and development of larval marine fish (Sargent et al. 1997; Drillet et al. 2006a; van der Meeren et al. 2008) and can be manipulated through the algae they are fed (Stottrup et al. 1999; Lee et al. 2006). Advances in copepod production have occurred and nauplii have been successfully used as a live feed (Stottrup 2003; Lee et al. 2005). Advantages of feeding copepods as a primary or supplemental diet have been demonstrated repeatedly (Kraul et al. 1992; Shields et al. 1999; Payne et al. 2001; Evjemo et al. 2003; Wilcox et al. 2006). Currently, however, sufficient quantities of copepod nauplii are not readily available to satisfy the live feed demand of most commercial facilities. Therefore, copepod nauplii must be used efficiently as a live feed, and it should be evaluated to define the culture methods and optimal feeding protocols for various species of marine fish larvae.

Since 2003, a population of the calanoid copepods Pseudodiaptomus pelagicus has been kept in continuous culture by AlgaGen, LLC (Vero Beach, Florida) and, beginning in 2007, at the University of Florida's Indian River Research and Education Center (IRREC). Pseudodiaptomus pelagicus has many advantageous characteristics that make it well suited for mass production, including the ability to tolerate heavy aeration, suspended solids, and sedimentation, to survive and reproduce on a single microalgal species, and to attain densities of at least 5 individuals $/ \mathrm{mL}$. Furthermore, recent studies have determined

\footnotetext{
${ }^{1}$ In this notation, the number to the left of the colon is the number of carbon atoms in the compound, the number immediately to the right of the colon is the number of double bonds, and the number after the hyphen indicates the position of the first double bond from the methyl end.
}

optimal temperature (Rhyne et al. 2009) and salinity (Ohs et al. 2010b) ranges for the species.

The Florida pompano Trachinotus carolinus (hereafter, pompano) is a highly prized commercial and recreational marine fish species distributed along the South Atlantic and Gulf coasts of the United States (Muller et al. 2002). Low harvests of wild populations coupled with rising market demand have increased interest in developing culture techniques for this species (Muller et al. 2002; Weirich et al. 2006). Recent advances in pompano larviculture have increased survival of day-9 larvae to approximately $35 \%$ by defining the optimal rotifer enrichments and feeding protocols; these protocols consist of feeding enriched rotifers Brachionus plicatilis for the first $9 \mathrm{~d}$ posthatch (DPH; Cavalin and Weirich 2009), introducing nauplii of brine shrimp Artemia spp. at about $10 \mathrm{DPH}$, and weaning to an artificial feed at about 14 DPH (Weirich and Riley 2005). In evaluations of other marine fish larvae (Rainuzzo et al. 1997; Sargent et al. 1997; Stottrup 2000; Hamre et al. 2008), copepods provided a nutritional advantage during the first feeding phase. To date, no studies have examined the performance of pompano larvae fed copepods.

A series of experiments were conducted to determine the effects of feeding nauplii of the calanoid copepod $P$. pelagicus to pompano larvae during the initial feeding phase. Growth, survival, and lipid composition were compared among dietary treatments to determine the optimal feeding regime.

\section{METHODS}

Water treatment.- Larval pompano were cultured in natural seawater (32-35 g/L salinity) that was chlorinated $(150 \mathrm{mg} / \mathrm{L})$ with sodium hypochlorite for $24 \mathrm{~h}$ then aerated for $24-48 \mathrm{~h}$. If chlorine was then detected in the water, it was neutralized with sodium thiosulfate. Sterile seawater was pumped into the hatchery facility, passed through 50- and 5- $\mu \mathrm{m}$-mesh bag filters, and stored in a 3,500-L polyethylene tank. That water was continuously circulated through an 80-W ultraviolet sterilizer (Emperor Aquatics, Pottstown, Pennsylvania) at a rate of $170-220 \mathrm{~L} / \mathrm{min}$, providing a sterilization intensity of $30,000-90,000 \mu \mathrm{W} / \mathrm{cm}^{2}$. As water exited the holding tank, it passed through 1.0- and $0.5-\mu \mathrm{m}$ (pore size) cartridge filters.

Spawning and egg incubation.-Pompano eggs were acquired from the U.S. Department of Agriculture, Agricultural Research Service (USDA-ARS), Center for Reproduction and Larviculture, located on the campus of Harbor Branch Oceanographic Institute at Florida Atlantic University in Fort Pierce, Florida. Volitional spawning of broodstock by using a gonadotropin-releasing hormone analog (GnRHa) was achieved following procedures described by Weirich and Riley (2007). Eggs were transported to IRREC ( $\sim 30 \mathrm{~min})$ and incubated in static 55-L (trials 1 and 2) or 200-L (trial 3) circular, conicalbottom fiberglass tanks at a temperature of $26^{\circ} \mathrm{C}$ and a salinity of $35 \mathrm{~g} / \mathrm{L}$ with light aeration. Hatching occurred $30-37 \mathrm{~h}$ postfertilization. Within $8 \mathrm{~h}$ posthatch, aeration of incubation tanks 
TABLE 1. Diets of Florida pompano larvae during three experimental trials. Values are the number of live food organisms $(\mathrm{CN}=$ copepod nauplii, $\mathrm{R}=$ rotifers $)$ fed per milliliter per day. The standard reference diet (SRD) and Mix diet were fed to larvae four times daily $(0900,1300,1700$, and 2100 hours). Days posthatch that the feed was given are provided in parentheses. Following the 1-d and 3-d treatments, larvae were fed the SRD for the remainder of each trial.

\begin{tabular}{|c|c|c|c|c|c|}
\hline Trial & $1-d$ & $3-d$ & Copepods & Mix & SRD \\
\hline 1 & & $2.50 \mathrm{CN}(3)$ & & & \\
\hline \multirow[t]{3}{*}{2} & $2.43 \mathrm{CN}(2)$ & $2.43 \mathrm{CN}(2)$ & & & $2.50 \mathrm{R}-(2-6)$ \\
\hline & & $3.10 \mathrm{CN}$ (3) & & & \\
\hline & & $3.41 \mathrm{CN}(4)$ & & & \\
\hline & & $3.00 \mathrm{CN}(3)$ & $3.00 \mathrm{CN}(3)$ & $0.50 \mathrm{CN}-(2-8)$ & \\
\hline & & $4.50 \mathrm{CN}(4)$ & $4.50 \mathrm{CN}(4)$ & & \\
\hline & & & $6.25 \mathrm{CN}(5)$ & & \\
\hline & & & $7.80 \mathrm{CN}(6)$ & & \\
\hline & & & $8.00 \mathrm{CN}(7)$ & & \\
\hline
\end{tabular}

was increased to allow even distribution of larvae. Ten volumetric subsamples were then taken from each incubation tank for quantification of larvae before volumetric stocking of the experimental system.

Larval rearing.- Three larval rearing trials, two lasting $7 \mathrm{~d}$ and one lasting $9 \mathrm{~d}$, were conducted in a flow-through system consisting of twenty-eight 13-L cylindrical, flat-bottom fiberglass tanks with black walls and white bottoms. An artificial photoperiod of $14 \mathrm{~h}$ light and $10 \mathrm{~h}$ dark was maintained. Newly hatched larvae (0 DPH) were volumetrically stocked into each tank at a density of 50 larvae/L. The initial water flow rate was $27 \mathrm{~mL} / \mathrm{min}$ (300\% total daily tank volume [TDTV]), gentle aeration was provided, and daytime surface light levels were maintained below 150 lx (Milwaukee Instruments Luxmeter Model SM700; Rocky Mount, North Carolina) for the first $2 \mathrm{~d}$. Beginning on $2 \mathrm{DPH}$, tanks were inoculated daily with Tahitian strain Isochrysis galbana (T-ISO) microalgae to a density of 100,000-380,000 cells $/ \mathrm{mL}$. At this time, water flow was increased to $37 \mathrm{~mL} / \mathrm{min}$ (400\% TDTV), aeration was increased slightly, and daytime surface light levels were increased to 1,000-1,550 lx. At $4 \mathrm{DPH}$, aeration was again increased slightly and water flow was adjusted to $55 \mathrm{~mL} / \mathrm{min}$ (600\% TDTV). At $7 \mathrm{DPH}$, aeration was again increased slightly and water flow adjusted to $72 \mathrm{~mL} / \mathrm{min}(800 \%$ TDTV) for the remainder of the trial. In each replicate tank, temperature, salinity, dissolved oxygen, and $\mathrm{pH}$ were monitored daily (YSI Inc., model 556 MPS). Total ammonia nitrogen (TAN) and nitrite-nitrogen $\left(\mathrm{NO}_{2}-\mathrm{N}\right)$ were also measured daily with a Hach DR/4000U spectrophotometer.

Diets.-Three diets, each replicated six times, were examined in trials 1 and 2: a standard reference diet (SRD) consisting solely of enriched rotifers; a 1-d diet; and a 3-d diet (Table 1). In trial 3, four diets, each replicated seven times, were examined: the SRD; an all copepod diet; a 3-d diet; and a mixed diet. The SRD was adapted from pompano larviculture protocols established by USDA-ARS (Weirich and Riley 2005; Cavalin and Weirich 2009). Beginning on 2 DPH, larvae were fed diets consisting of enriched S-strain rotifers Brachionus plicatilis having a body width of $117.5 \pm 19.8 \mu \mathrm{m}$ (Cavalin and Weirich 2009), P. pelagicus nauplii with a body width of $93.2 \pm$ $13.7 \mu \mathrm{m}$ (Cassiano 2009), or both. When copepod nauplii were fed, an internal standpipe with a 50- $\mu$ m nylon mesh screen was used to retain copepods; when rotifers were fed, an internal standpipe with a $240-\mu \mathrm{m}-\mathrm{mesh}$ nylon screen was used to flush rotifers. An internal standpipe with a $240-\mu \mathrm{m}-\mathrm{mesh}$ nylon screen was used when feeding the mixed diet.

Rotifer culture and enrichment.-Rotifers were cultured at $26^{\circ} \mathrm{C}$ and a salinity of $20 \mathrm{~g} / \mathrm{L}$ in a 120 -L cylindrical, conicalbottom fiberglass tank and a 950-L cylindrical, flat-bottom fiberglass tank. Rotifers were fed 7.5 L of T-ISO (10-15 million cells/mL) and Culture Selco (INVE Aquaculture, Inc.), a supplemental yeast-based rotifer diet, twice daily during the trials according to manufacturer's instructions. Approximately 5-25 million rotifers were harvested daily for enrichment before being fed to fish larvae. Rotifers were enriched in 10-L buckets with Ori-Green (Skretting) following manufacturer instructions for $3 \mathrm{~h}$ at $27-28^{\circ} \mathrm{C}$. After the enrichment period, the rotifers were rinsed with $20 \mathrm{~g} / \mathrm{L}$ seawater, placed in fresh $20 \mathrm{~g} / \mathrm{L}$ salinity water (10-L) and the temperature was reduced to approximately $15^{\circ} \mathrm{C}$ by placing frozen water bottles into the bucket. Once the temperature was reduced, the bucket of rotifers was stored in a refrigerator at $5-10^{\circ} \mathrm{C}$. Enriched rotifers were fed within $24 \mathrm{~h}$ of cold storage.

Copepod culture.- Pseudodiaptomus pelagicus were batchcultured at $28-30^{\circ} \mathrm{C}$ and a salinity of $22-25 \mathrm{~g} / \mathrm{L}$ in eight $200-\mathrm{L}$ cylindrical, flat-bottom polyethylene tanks and an 1,800-L cylindrical, conical-bottom tank. Aeration was kept moderate and sponge filters were used within each tank. During trials 1 and 2, 
each 200-L population was fed 1-2 L of T-ISO (15-20 million cells $/ \mathrm{mL}$ ) daily. During trial 3, copepod populations were fed a 1:1 mixture by volume of T-ISO (15-20 million cells $/ \mathrm{mL})$ and Thalassiosira weissflogii (TW) (1-2 million cells/mL) daily; each $200-\mathrm{L}$ population was fed $1-2 \mathrm{~L}$ of the algal mix and the 1,800-L population was fed 18-24 L. Nauplii were harvested twice daily from each tank via floating airlifts (Cassiano 2009). Harvested nauplii were then placed in a graduated bucket containing $22 \mathrm{~g} / \mathrm{L}$ salinity water, volumetrically sampled, quantified, and fed to larvae.

Sample collection and morphometric analysis.-Morphometric analysis of fish larvae was adapted from techniques described in Cavalin and Weirich (2009). On 0 DPH, 60 yolk sac larvae were randomly selected from the incubation tank for morphometric analysis. Thereafter, 10 larvae from each experimental tank were randomly sampled on 3, 6, and 9 DPH for morphometric analysis. Larvae were euthanized by brief immersion in cold water $\left(\sim 4^{\circ} \mathrm{C}\right)$, placed on a glass slide, and photographed by using a dissecting microscope at $40 \times$ magnification with a digital camera (Sony model DCRA-C171). For calibration, a 0.01-mm micrometer was photographed before each photo series. SigmaScan Pro 5.0 image analysis software (SPSS Science) was used to measure photographed larvae. Standard length (SL; the distance parallel to the longitudinal axis of the body from the tip of the snout to the distal end of the hypural bone) and body depth (BD; the distance perpendicular to the longitudinal axis of the body from the insertion of the first dorsal spine to the ventral-most point on the base of the body) were measured and recorded. When measuring yolk sac larvae, BD was considered the distance perpendicular to the longitudinal axis from the dorsal crest through the midpoint of the yolk sac to the ventral-most point of the body. At the conclusion of each larval rearing trial, larvae from each tank were individually counted to determine survival.

Fatty acid analysis.-For trials 2 and 3, larvae were collected at $0 \mathrm{DPH}$ and at the conclusion of the trial from each treatment for fatty acid analysis. Also collected for fatty acid analysis during trials 2 and 3 were copepod nauplii and enriched rotifers. Larvae and live feed samples were rinsed with deionized water, placed in plastic vials, flushed with nitrogen, and stored in a freezer $\left(-80^{\circ} \mathrm{C}\right)$ until analyzed. Samples were packed in solid $\mathrm{CO}_{2}$ and shipped to Roger Williams University, Bristol, Rhode Island, for fatty acid analysis. Total lipids were extracted from lyophilized samples with chloroform : methanol mixture (2:1 by volume) as described by Folch et al. (1957). Between 20 and $50 \mathrm{mg}$ of the dried tissue was ground in a tissue grinder. The tissue was then resuspended in $10 \mathrm{~mL}$ of a chloroform : methanol ( $2: 1$ by volume) mixture and vacuum-filtered. Fatty acid methyl esters (FAMEs) were prepared by transesterification according to the method of Drillet et al. (2006b). After extraction, the solvent was evaporated and the product was reconstituted in $2 \mathrm{~mL}$ of toluene : methanol : acetyl chloride mixture (40:50:10 by volume), and $0.5 \mathrm{~mL}$ of $1.04 \mathrm{mg} / \mathrm{mL}$ heptadecanoic acid
(17:0) was added as an internal standard. The mixture was then heated in a water bath at $60^{\circ} \mathrm{C}$ for $60 \mathrm{~min}$. Exactly $1 \mathrm{~mL}$ of aqueous sodium bicarbonate (5\% by weight) was added. The upper organic layer was removed and saved, the original solution was washed twice with heptane, and the upper organic layers were combined. The solvent was then evaporated with a gentle stream of warm nitrogen. The methyl esters were resuspended in $1 \mathrm{~mL}$ of chloroform.

A $1.0-\mu \mathrm{L}$ aliquot of each FAME preparation was analyzed on an Agilent 6850 gas chromatograph (GC) coupled with an Agilent 5975B mass-sensitive detector. The GC was equipped with an Agilent or J\&W DB-23 column $(60 \mathrm{~m} \times 0.25 \mathrm{~mm}$ [internal diameter] with a $0.25-\mu \mathrm{m}$ film thickness). The inlet temperature was $250^{\circ} \mathrm{C}$, and helium was used as the carrier gas, with a $2.1 \mathrm{~mL} / \mathrm{min}$ flow rate and splitless injection. The oven temperature was initially set to $50^{\circ} \mathrm{C}$ for $1 \mathrm{~min}$, increased to $175^{\circ} \mathrm{C}$ at a rate of $25^{\circ} \mathrm{C} / \mathrm{min}$, and then increased to $235^{\circ} \mathrm{C}$ at a rate of $4^{\circ} \mathrm{C} / \mathrm{min}$ and held for $5 \mathrm{~min}$. The FAME peaks were identified by comparing their retention times and mass spectrographs with those of known FAMEs and corroborated with the National Institute of Standards and Technology MS Search 2.0 mass spectral library. The concentration of the FAMEs in each sample were determined by using the quantification feature on the ChemStation (Agilent Technologies) software, and the peak areas of the known FAMEs standards (Supelco, Inc., catalogue number 18919-1AMP) were compared with those determined for the samples to confirm accuracy.

Statistical analysis.-All statistical analyses were performed with SAS version 8.02 software (SAS, Cary, North Carolina). Percentage data were arcsine-square-root transformed before analysis. Treatment means of all dependent variables were subjected to one-way analysis of variance (ANOVA) according to the general linear model (PROC GLM) procedure of SAS. A least significant difference test (LSD) was used to compare treatment means for larval growth and survival when the ANOVA was significant. All statistical tests were considered significant when $P$ equaled 0.05 or less.

\section{RESULTS}

\section{Water Quality}

Water-quality parameters measured during the experimental trials were within suitable ranges for pompano larviculture (Weirich and Riley 2005). In trial 1, temperature ranged from $24.2^{\circ} \mathrm{C}$ to $27.2^{\circ} \mathrm{C}$, salinity from 34.4 to $35.6 \mathrm{~g} / \mathrm{L}$, dissolved oxygen from 5.02 to $6.25 \mathrm{mg} / \mathrm{L}, \mathrm{pH}$ from 7.94 to 8.13 , TAN from 0.03 to $0.18 \mathrm{mg} / \mathrm{L}$, and $\mathrm{NO}_{2}-\mathrm{N}$ from 0.0020 to $0.0493 \mathrm{mg} / \mathrm{L}$. In trial 2, temperature ranged from $22.7^{\circ} \mathrm{C}$ to $26.8^{\circ} \mathrm{C}$, salinity from 34.8 to $35.6 \mathrm{~g} / \mathrm{L}$, dissolved oxygen from 5.42 to $6.54 \mathrm{mg} / \mathrm{L}, \mathrm{pH}$ from 7.94 to 8.26 , TAN from 0.00 to $0.74 \mathrm{mg} / \mathrm{L}$, and $\mathrm{NO}_{2}-\mathrm{N}$ from 0.0001 to $0.0407 \mathrm{mg} / \mathrm{L}$. In trial 3, temperature ranged from $26.2^{\circ} \mathrm{C}$ to $28.5^{\circ} \mathrm{C}$, salinity from 31.6 to $36.0 \mathrm{~g} / \mathrm{L}$, dissolved oxygen from 5.46 to $6.55 \mathrm{mg} / \mathrm{L}$, pH from 8.02 to 8.30 , TAN 
TABLE 2. Growth of Florida pompano larvae fed different dietary treatments during the experimental trials; values are the standard length (SL) or body depth $(\mathrm{BD})(\mathrm{mm}$; mean $\pm \mathrm{SD})$ at 3,6 , and $9 \mathrm{~d}$ posthatch $(\mathrm{DPH})$. Statistical significance within trials is indicated by different letters within a row $(P \leq 0.05)$.

\begin{tabular}{|c|c|c|c|c|c|c|c|c|}
\hline \multirow[b]{2}{*}{ Trial } & \multirow[b]{2}{*}{ Variable } & \multirow[b]{2}{*}{ DPH } & \multicolumn{6}{|c|}{ Dietary treatments } \\
\hline & & & $1-d$ & $3-d$ & Copepod & Mix & SRD & $P$-value \\
\hline \multirow[t]{4}{*}{1} & SL & 3 & $2.86 \pm 0.25 \mathrm{z}$ & $2.87 \pm 0.18 \mathrm{z}$ & & & $2.85 \pm 0.36 \mathrm{z}$ & 0.9449 \\
\hline & & 6 & $3.22 \pm 0.52 \mathrm{y}$ & $3.54 \pm 0.22 \mathrm{z}$ & & & $3.36 \pm 0.26 \mathrm{y}$ & $<0.0001$ \\
\hline & $\mathrm{BD}$ & 3 & $0.73 \pm 0.06 y$ & $0.76 \pm 0.06 \mathrm{zy}$ & & & $0.77 \pm 0.08 \mathrm{z}$ & 0.0429 \\
\hline & & 6 & $1.00 \pm 0.13 \mathrm{z}$ & $0.93 \pm 0.08 \mathrm{y}$ & & & $0.91 \pm 0.11 \mathrm{y}$ & $<0.0001$ \\
\hline \multirow[t]{4}{*}{2} & SL & 3 & $2.49 \pm 0.14 \mathrm{z}$ & $2.44 \pm 0.14 \mathrm{zy}$ & & & $2.40 \pm 0.20 \mathrm{y}$ & 0.0181 \\
\hline & & 6 & $3.73 \pm 0.37 \mathrm{z}$ & $3.48 \pm 0.47 \mathrm{y}$ & & & $3.29 \pm 0.44 \mathrm{x}$ & $<0.0001$ \\
\hline & $\mathrm{BD}$ & 3 & $0.79 \pm 0.06 \mathrm{z}$ & $0.79 \pm 0.06 \mathrm{z}$ & & & $0.71 \pm 0.05 \mathrm{y}$ & $<0.0001$ \\
\hline & & 6 & $0.98 \pm 0.11 \mathrm{z}$ & $0.95 \pm 0.13 \mathrm{z}$ & & & $0.88 \pm 0.09 \mathrm{y}$ & $<0.0001$ \\
\hline \multirow[t]{6}{*}{3} & SL & 3 & & $3.26 \pm 0.22 \mathrm{z}$ & $3.29 \pm 0.16 \mathrm{z}$ & $3.24 \pm 0.15 \mathrm{z}$ & $3.11 \pm 0.21 \mathrm{y}$ & $<0.0001$ \\
\hline & & 6 & & $3.78 \pm 0.31 \mathrm{y}$ & $3.82 \pm 0.31 \mathrm{zy}$ & $3.91 \pm 0.38 \mathrm{z}$ & $3.92 \pm 0.35 \mathrm{z}$ & 0.0300 \\
\hline & & 9 & & $4.25 \pm 0.29 \mathrm{x}$ & $4.08 \pm 0.37 \mathrm{w}$ & $4.56 \pm 0.52 \mathrm{z}$ & $4.40 \pm 0.46 y$ & $<0.0001$ \\
\hline & $\mathrm{BD}$ & 3 & & $0.75 \pm 0.06 z$ & $0.74 \pm 0.06 \mathrm{z}$ & $0.75 \pm 0.06 \mathrm{z}$ & $0.66 \pm 0.05 y$ & $<0.0001$ \\
\hline & & 6 & & $0.94 \pm 0.12 \mathrm{z}$ & $0.95 \pm 0.12 \mathrm{z}$ & $0.99 \pm 0.14 \mathrm{z}$ & $0.98 \pm 0.13 \mathrm{z}$ & 0.1180 \\
\hline & & 9 & & $1.11 \pm 0.14 \mathrm{x}$ & $1.03 \pm 0.14 \mathrm{w}$ & $1.24 \pm 0.21 \mathrm{z}$ & $1.18 \pm 0.21 \mathrm{y}$ & $<0.0001$ \\
\hline
\end{tabular}

from 0.00 to $0.40 \mathrm{mg} / \mathrm{L}$, and $\mathrm{NO}_{2}-\mathrm{N}$ from 0.0018 to 0.0990 $\mathrm{mg} / \mathrm{L}$.

\section{Larval Growth}

In trial 1, 0-DPH pompano larvae had an SL of $2.77 \pm$ $0.22 \mathrm{~mm}$ (mean $\pm \mathrm{SD}$ ) and a BD of $0.89 \pm 0.06 \mathrm{~mm}$. At $3 \mathrm{DPH}$, the mean SL of larvae did not differ among diets $(P=0.9449)$, whereas the mean BD of larvae was significantly different among diets $(P=0.0429$; Table 2$)$. At $6 \mathrm{DPH}$, there were significant differences in the mean SL $(P<0.0001)$ and $\mathrm{BD}(P<0.0001)$ of larvae among diets. Larvae fed the 1 -d diet had significantly greater BD on $6 \mathrm{DPH}$, whereas larvae fed the 3-d diet had significantly greater SL than larvae fed the other diets.

In trial 2, 0-DPH pompano larvae had an SL of $2.41 \pm 0.22$ $\mathrm{mm}$ and a $\mathrm{BD}$ of $0.81 \pm 0.07 \mathrm{~mm}$. At $3 \mathrm{DPH}$, there were significant differences in mean SL $(P=0.0181)$ and BD $(P<$ $0.0001)$ of larvae among diets. At 6 DPH, there were significant differences in the mean SL $(P<0.0001)$ and BD $(P<0.0001)$ of larvae among diets; larvae fed both copepod diets exhibited greater growth than larvae fed the SRD.

In trial 3, 0-DPH pompano larvae had an SL of $2.97 \pm 0.14$ $\mathrm{mm}$ and a BD of $0.90 \pm 0.08 \mathrm{~mm}$. At $3 \mathrm{DPH}$, there were significant differences in mean SL $(P<0.0001)$ and BD $(P<$ 0.0001 ) of larvae among diets. At $6 \mathrm{DPH}$, the mean SL of larvae was significantly different among diets $(P=0.0300)$, but the mean BD of larvae was not significantly different among diets $(P=0.1180)$. At $9 \mathrm{DPH}$, there were significant differences in mean SL $(P<0.0001)$ and BD $(P<0.0001)$ of larvae among diets. Larvae fed the mixed diet recorded the highest SL and BD on $9 \mathrm{DPH}$, whereas the SL and BD of larvae fed the 3-d and copepod diets were lower than larvae fed the SRD and mixed diets.

\section{Survival}

At the conclusion of each trial, there were significant differences in mean survival (trial 1: $P=0.0173$; trial 2: $P=0.0011$; and trial 3: $P=0.0010$ ) among diets (Table 3 ). In every trial, the highest survival was recorded for pompano larvae fed copepods, and the survival of larvae fed the 1-d diet in trial 1 was nearly twice that of larvae fed the SRD.

\section{Total Lipid and Fatty Acid Composition}

Fatty acid composition, DHA : EPA ratios, and EPA : ARA ratios of live feeds, 0-DPH pompano larvae, and 7-DPH larvae (trial 2) or 9-DPH larvae (trial 3) are presented in Tables 4 and 5 , respectively. The DHA content was higher in the copepod nauplii than in rotifers. Copepods also had higher levels of total n-3 fatty acids and lower levels of total n-6 fatty acids. Copepod nauplii fed T-ISO during trial 2 had higher DHA than did nauplii fed T-ISO/TW during trial 3. However, nauplii fed T-ISO/TW had higher levels of EPA and total n-3 fatty acids than the copepods fed T-ISO.

In trial 2, the percentage of DHA, EPA, and total n-3 fatty acids were slightly higher in pompano larvae fed copepods than in those fed the SRD. Docosahexaenoic acid and total n-3 fatty acids were also higher in larvae fed the 3-d diet than in larvae fed the 1-d diet. Eicosapentaenoic acid was higher in pompano larvae fed the copepod diet than in larvae fed the SRD in trial 3. Docosahexaenoic acid and total n-3 fatty acid content were also slightly higher for larvae fed the 3-d and copepod treatments than for those fed the mixed and SRD treatments. 
TABLE 3. Percent survival (mean \pm SD) of 7-DPH (trials 1 and 2) and 9-DPH (trial 3) Florida pompano larvae fed different dietary treatments during three experimental trials. Statistical significance within trials is indicated by different letters within a row $(P \leq 0.05)$.

\begin{tabular}{lcccccc}
\hline Trial & $1-\mathrm{d}$ & 3 -d & Copepods & Mix & SRD & $P$-value \\
\hline 1 & $38.6 \pm 7.8 \mathrm{z}$ & $29.0 \pm 4.6 \mathrm{zy}$ & & & $20.8 \pm 10.5 \mathrm{y}$ & 0.0173 \\
2 & $63.4 \pm 7.6 \mathrm{y}$ & $71.5 \pm 5.1 \mathrm{z}$ & & & $53.6 \pm 5.0 \mathrm{x}$ & 0.0011 \\
3 & & $34.0 \pm 7.6 \mathrm{x}$ & $57.3 \pm 15.4 \mathrm{z}$ & $37.8 \pm 2.1 \mathrm{yx}$ & $45.5 \pm 9.5 \mathrm{y}$ & 0.0010 \\
\hline
\end{tabular}

\section{DISCUSSION}

Production of many marine fish species is currently impeded by poor performance during the larval phase. Traditional live feeds, such as rotifers and brine shrimp, can be nutritionally deficient, may not constitute the appropriate size range, and may not elicit a feeding response, making them inadequate for many marine fish species (Stottrup and Norsker 1997; Sargent et al. 1999a,1999b; Lee et al. 2005). Advances in copepod culture methods have increased their use as a live feed (Payne and Rippingale 2001; Lee et al. 2005; Marcus and Wilcox 2007). The current experiments are the first report of intensive production of the calanoid copepod P. pelagicus for feeding marine fish larvae and the first report of feeding copepods to pom- pano larvae. The goal of these experiments was to measure growth, survival, and lipid composition of larval pompano fed $P$. pelagicus nauplii in various feeding regimes and to compare results with those larvae fed the SRD of rotifers. Results indicated significant advantageous effects on larval performance, similar to reports of other marine fish species fed copepods (Kraul et al. 1992; Shields et al. 1999; Evjemo et al. 2003; Lee et al. 2005; Rajkumar and Kumaraguru vasagam, 2006; Wilcox et al. 2006; Battaglene and Cobcroft 2007; Olivotto et al. 2008).

Feeding copepod nauplii in addition to feeding rotifers has proven beneficial for the production of other marine fish larvae. Toledo et al. (1999) fed nauplii of Acartia tsuensis to larvae of orange-spotted grouper Epinephelus coioides from 2 to

TABLE 4. Fatty acid composition (\% total fatty acids) and DHA : EPA and EPA : ARA ratios of Florida pompano larvae at $0 \mathrm{~d}$ posthatch (DPH) of live feeds fed to larvae, and of 7-DPH larvae fed different dietary treatments during trial 2. See text for additional details.

\begin{tabular}{|c|c|c|c|c|c|c|}
\hline \multirow[b]{2}{*}{ Fatty acid or ratio } & \multirow[b]{2}{*}{$0 \mathrm{DPH}$} & \multicolumn{2}{|c|}{ Live feeds } & \multicolumn{3}{|c|}{ Dietary treatments } \\
\hline & & Nauplii & Rotifers & $1-\mathrm{d}$ & $3-d$ & SRD \\
\hline $14: 0$ & 0.12 & 9.93 & 5.85 & 3.07 & 3.86 & 1.07 \\
\hline $14: 1$ & 2.46 & & & & & \\
\hline $15: 1$ & 0.21 & & & & & \\
\hline $16: 0$ & 0.23 & 8.77 & 25.15 & 15.97 & 15.54 & 15.21 \\
\hline $16: 1$ & 15.21 & 3.15 & 11.70 & 3.09 & 3.28 & 2.08 \\
\hline 18:0 & 0.67 & 1.51 & 8.34 & 9.87 & 8.77 & 11.03 \\
\hline 18:1 (n-9) & 3.31 & 13.94 & 5.48 & 14.52 & 12.73 & 12.91 \\
\hline $18: 2(n-6)$ & 23.37 & 7.40 & 16.66 & 5.69 & 4.79 & 5.09 \\
\hline $18: 3(n-3)$ & 1.99 & 5.41 & 4.20 & 2.37 & 2.76 & 1.54 \\
\hline $18: 3(n-6)$ & 6.75 & & & & & \\
\hline 20:0 & 3.83 & & & & & 3.00 \\
\hline 20:1 (n-9) & 0.24 & & 6.23 & 1.54 & 0.84 & 1.68 \\
\hline $20: 2(n-6)$ & 0.66 & & & & 1.04 & 2.00 \\
\hline $20: 3(n-3)$ & 0.20 & & & 2.23 & & \\
\hline $20: 3(n-6)$ & 0.44 & & & & & \\
\hline $20: 4(n-6)$ & 1.74 & & & 1.61 & 1.65 & 1.93 \\
\hline $20: 5(n-3)$ & 4.00 & & 7.44 & 3.15 & 2.45 & 2.06 \\
\hline $21: 0$ & 0.48 & & & & 0.88 & 7.97 \\
\hline $22: 6(n-3)$ & 29.09 & 18.40 & 8.94 & 36.89 & 40.11 & 32.43 \\
\hline 24:0 & & & & & 0.91 & \\
\hline DHA : EPA & 7.27 & & 1.20 & 11.71 & 16.37 & 15.74 \\
\hline EPA : ARA & 2.30 & & & 1.96 & 1.48 & 1.07 \\
\hline Total (n-3) & 35.28 & 23.81 & 20.04 & 44.64 & 45.32 & 36.03 \\
\hline Total (n-6) & 32.96 & 7.40 & 16.66 & 7.30 & 7.48 & 9.02 \\
\hline
\end{tabular}


TABLE 5. Fatty acid composition (\% total fatty acids) and DHA : EPA and EPA : ARA ratios of Florida pompano larvae at $0 \mathrm{~d}$ posthatch (DPH) of live feeds fed to larvae, and of 9-DPH larvae fed different dietary treatments during trial 3. See text for additional details.

\begin{tabular}{|c|c|c|c|c|c|c|c|}
\hline \multirow[b]{2}{*}{ Fatty acid or ratio } & \multirow[b]{2}{*}{$0 \mathrm{DPH}$} & \multicolumn{2}{|c|}{ Live feeds } & \multicolumn{4}{|c|}{ Dietary treatments } \\
\hline & & Nauplii & Rotifers & $3-d$ & Copepods & Mix & SRD \\
\hline 14:0 & 1.34 & 7.30 & 2.16 & 1.49 & & 2.73 & 1.70 \\
\hline 14:1 & & 2.45 & & & & & \\
\hline $15: 0$ & 0.33 & & 39.60 & & 0.98 & & \\
\hline $15: 1$ & 0.50 & & & & 0.77 & & \\
\hline $16: 0$ & 16.37 & 20.91 & 0.48 & 18.12 & 18.33 & 19.39 & 16.75 \\
\hline $16: 1$ & 4.59 & 7.47 & 5.71 & 1.62 & 1.34 & 2.04 & 1.72 \\
\hline $17: 1$ & 0.61 & & & & & & 1.55 \\
\hline 18:0 & 3.30 & 7.07 & 5.21 & 13.59 & 11.88 & 13.70 & 11.29 \\
\hline 18:1 (n-9) & 23.36 & 13.38 & 17.84 & 12.61 & 9.40 & 13.80 & 13.35 \\
\hline $18: 2(n-6)$ & 12.06 & 6.81 & 14.39 & 9.93 & 2.98 & 7.70 & 7.07 \\
\hline $18: 3(n-3)$ & 1.93 & 2.13 & 2.33 & 1.01 & 0.69 & 1.67 & 1.16 \\
\hline $18: 3(n-6)$ & 0.60 & & & & & & \\
\hline 20:0 & & & & & 0.96 & & \\
\hline 20:1 (n-9) & 0.63 & & 2.03 & 1.47 & 1.61 & 1.84 & 1.50 \\
\hline $20: 2(n-6)$ & 0.99 & & 0.69 & & & & 1.82 \\
\hline $20: 3(n-3)$ & & & & & & & 0.88 \\
\hline $20: 3(n-6)$ & 0.59 & & & & & & \\
\hline $20: 4(n-6)$ & 1.61 & 2.46 & 1.02 & 2.38 & 1.89 & 1.93 & 2.16 \\
\hline $20: 5$ (n-3) & 2.65 & 16.90 & 3.49 & 2.22 & 3.46 & 2.23 & 2.15 \\
\hline $21: 0$ & & & & & 3.09 & & 3.51 \\
\hline $22: 2$ & & & & & 1.71 & & \\
\hline $22: 6(n-3)$ & 28.55 & 13.13 & 5.05 & 35.56 & 40.67 & 32.99 & 33.40 \\
\hline DHA : EPA & 10.77 & 0.78 & 1.45 & 16.02 & 11.75 & 14.79 & 15.53 \\
\hline EPA : ARA & 1.65 & 6.87 & 3.42 & 0.93 & 1.83 & 1.16 & 1.00 \\
\hline Total (n-3) & 33.13 & 32.16 & 10.87 & 38.79 & 44.82 & 36.89 & 37.59 \\
\hline Total (n-6) & 15.85 & 9.27 & 16.10 & 12.31 & 4.87 & 9.63 & 11.05 \\
\hline
\end{tabular}

$6 \mathrm{DPH}$, then fed a rotifer diet for the duration of the trial. Those larvae had improved feeding incidence, growth, and survival compared with larvae fed rotifers during the entire trial (Toledo et al. 1999). First-feeding larvae of turbot Psetta maxima (also known as Scophthalmus maximus) had greater growth and survival when fed Tisbe holothuriae nauplii from 3 to 6 DPH before switching to rotifers than larvae fed rotifers for the entire trial (Stottrup and Norsker 1997). Payne et al. (2001) fed pink snapper Pagrus auratus larvae on nauplii of Gladioferens imparipes from 4 to $10 \mathrm{DPH}$ and then switched to a rotifer diet. Beginning on $6 \mathrm{DPH}$, growth observed in larvae fed copepods was greater than that for larvae fed rotifers for the entire trial (Payne et al. 2001). Additionally, survival and swim bladder inflation were greater for larvae fed copepods (Payne et al. 2001).

In the present study, copepod nauplii fed to pompano larvae for either 1 or 3 days before transitioning to the SRD had beneficial effects. Various feeding rates for each period of copepod provision resulted in increased survival and growth of larval pompano. Advantages in the performance of pompano larvae fed the 1-d diet rather than the SRD were consistently demonstrated. Results from these trials indicate that feeding copepod nauplii to pompano larvae for as little as the first day of feeding at a daily rate of 2-3 nauplii/ $/ \mathrm{mL}$ improved survival and growth.

In trial 1, the survival of pompano larvae fed the 3-d diet was similar to the survival of larvae fed the 1-d diet, which may have been a reflection of low prey density in the 3-d diet. During trial 2, larvae fed the 3-d diet were fed 0.30, 0.60, and 0.41 nauplii/ $/ \mathrm{mL}$ more on $2-4 \mathrm{DPH}$, respectively (Table 1 ). This increased feeding rate probably supplied more nutrients during the first three feeding days, which may have increased survival of larvae fed the 3-d diet during trial 2. Pompano larvae fed the 3-d diet during trial 3 did not perform as well as larvae fed the SRD. During this trial, copepods fed the microalgae TW had increased EPA content and a decreased DHA : EPA ratio; this may have contributed to the poorer larval pompano performance.

The mixed diet produced similar survival but increased growth when compared to larvae fed the SRD. By feeding a 4:1 ratio of enriched rotifers to copepod nauplii, an adequate live feed density was maintained (Weirich and Riley 2005; 
Cavalin and Weirich 2009) while avoiding possible nutritional deficiencies of rotifers. Payne et al. (2001) reported significant increases in growth when pink snapper larvae were fed a 4:1 ratio of enriched rotifers and copepod nauplii rather than enriched rotifers. Larvae of southern flounder Paralichthys lethostigma had significantly greater growth and survival when fed a 1:1 mixture of enriched rotifers and A. tonsa nauplii than larvae fed only enriched rotifers (Wilcox et al. 2006). Yellowtail clownfish Amphiprion clarkii larvae fed a 1:1 mixture of rotifers and Tisbe spp. nauplii also displayed significantly greater growth and survival than did larvae fed only rotifers or only Tisbe nauplii (Olivotto et al. 2008).

In trial 3, larvae fed only copepods during the entire larval trial registered the highest survival but had the lowest growth among the dietary treatments. The low growth was probably associated with an insufficient quantity or nutritional composition of the nauplii fed to the larvae. The high survival of larvae fed copepods likely reduced the availability of copepods per larvae. Some fish species, such as red snapper Lutjanus campechanus (Ogle et al. 2005), grouper E. coioides (Toledo et al. 1999), and West Australian dhufish Glaucosoma hebraicum (Payne et al. 2001) require copepod nauplii for optimal development during the larval phase. Pompano larviculture protocols do not appear to necessitate the use of copepods, although benefits of feeding copepod nauplii to larval pompano have been identified.

Adult $P$. pelagicus fed monoalgal diets consisting of TW produced on average 3-4 times more nauplii than did adults fed T-ISO (Ohs et al. 2010a). Therefore, in trial 3, a 1:1 mixture of T-ISO : TW was fed to $P$. pelagicus to increase nauplii production. This feeding protocol altered the DHA : EPA ratio by increasing the EPA in the copepods and the larvae (Tables 4, 5). Similarly, an insufficient ratio of DHA : EPA : ARA for marine fish larviculture was reported when the copepod $A$. tonsa was fed monoalgal diets of TW (Stottrup and Jensen 1990; Stottrup et al. 1999). Additionally, Atlantic cod Gadus morhua larvae fed A. tonsa nauplii that had been fed TW had the lowest growth of any of the treatment diets examined (St. John et al. 2001). Our attempt to increase $P$. pelagicus nauplii production by feeding T-ISO, an alga high in DHA, in a 1:1 mixture (by volume) with $\mathrm{TW}$, an alga high in EPA, did increase nauplii production; however, the decreased growth seen in the copepod and 3-d treatments examined in trial 3 may have resulted from the increased EPA content or the decreased DHA : EPA ratio (Reitan et al. 1997). Further investigation is necessary to clarify the effects of increased EPA and a decreased DHA : EPA ratio on larval pompano performance.

Improved survival and growth of marine fish larvae fed copepods associated with improved nutritional composition have been well documented (Shields et al. 1999; Evjemo et al. 2003; Rajkumar and Kumaraguru vasaham, 2006; Guangxing and Donghui 2009). Similarly, in trial 2, increased survival and growth at 6 DPH of larvae fed copepods were observed with higher levels of DHA and total n-3 fatty acids. Furthermore, higher survival and percentage DHA coincided with an in- creased duration in which copepods were fed. The higher DHA found in copepod-fed larvae probably came from the copepod nauplii, which contained nearly twice the percentage of DHA that the enriched rotifers provided. Unlike DHA, the comparisons of survival and growth to EPA and ARA content are ambiguous. In trial 3, no clear relationship is observed when comparing survival, growth, and duration of providing copepods in the diet to the content of DHA, EPA, ARA, and total n-3 fatty acids. Further research is warranted to understand the diet effect of copepods on the nutritional composition of marine fish larvae.

Linolenic acid (18:3[n-3]) and myristic acid (14:0) appeared to influence both growth parameters measured during trials 2 and 3. Within each trial we observed that an increase in SL of larvae was associated with increased levels of linolenic and myristic acids. In trial 2, an increased duration of copepods being fed was directly related to elevated levels of both linolenic and myristic acids, and greater SL. In trial 3, however, feeding copepods for a longer duration resulted in lower levels of both fatty acids as well as reduced length. An identical pattern was also displayed when comparing the effects of diet and these fatty acids on BD. In addition, oleic acid (18:1[n-9]) displayed a similar trend in terms of diet and effects on growth. Despite observation of these patterns, more research is necessary to understand the interactions of these fatty acids and their effects on the performance of larval marine fish.

To attain a sufficient quantity of nauplii for a commercial hatchery or for feeding copepods for extended periods, the scale of $P$. pelagicus production would have to increase. An appropriate scale at which to supply nauplii to a small commercial hatchery was tested and small-scale results were verified by Cassiano (2009). The larval culture tanks used in the current study were $13 \mathrm{~L}$. These results need to be verified in larger culture tanks.

\section{CONCLUSION}

This was the first report of intensive production of the calanoid \& copepod P. pelagicus for feeding larval marine fish and the first report of feeding copepods to pompano larvae. Incorporating copepods into a live feeds regime for pompano resulted in increased growth and survival, which further optimizes current methods for pompano production. Our results suggest a benefit of feeding copepods to pompano larvae during the initial feeding phase, which would reduce the quantity of copepod nauplii needed by a hatchery. The benefits of $P$. pelagicus nauplii as a live feed for pompano larvae have been demonstrated and a daily feeding rate of $2-3$ nauplii $/ \mathrm{mL}$ on $2-3$ DPH is recommended.

\section{ACKNOWLEDGMENTS}

We thank the Florida Department of Agriculture and Consumer Services Division of Aquaculture for funding this research. We thank Erik Stenn of AlgaGen, LLC of Vero Beach, Florida, for providing stock cultures of copepods and microalgae and for sharing culture expertise. We also thank Meghan 
Anderson, Fernando Cavalin, Kelly Chang, Shawn DeSantis, Matthew DiMaggio, Bryan Garr, Scott Grabe, John Marcellus, Amber Thomas, and Peter Woodward for assisting with various aspects of these experiments.

\section{REFERENCES}

Battaglene, S. C., and J. M. Cobcroft. 2007. Advances in the culture of striped trumpeter larvae: a review. Aquaculture 268:195-208.

Cassiano, E. J. 2009. Evaluation of the calanoid copepod Pseudodiaptomus pelagicus as a first feed for Florida pompano, Trachinotus carolinus, larvae. Master's thesis. University of Florida, Gainesville.

Cavalin, F., and C. R. Weirich. 2009. Larval performance of aquacultured Florida pompano (Trachinotus carolinus) fed rotifers (Brachionus plicatilis) enriched with selected commercial diets. Aquaculture 292:67-73.

Chesney, E. J. 2005. Copepods as live prey: a review of factors that influence the feeding success of marine fish larvae. Pages 133-150 in C.-S. Lee, P. J. O'Bryen, and N. H. Marcus, editors. Copepods in aquaculture. Blackwell Scientific Publications, Cambridge, Massachusetts.

Drillet, G., M. H. Iversen, T. F. Sorensen, H. Ramlov, T. Lund, and B. W. Hansen. 2006a. Effect of cold storage upon eggs of a calanoid copepod, Acartia tonsa (Dana) and their offspring. Aquaculture 254:714-729.

Drillet, G., N. O. G. Jorgensen, T. F. Sorensen, H. Ramlov, and B. W. Hansen. 2006b. Biochemical and technical observations supporting the use of copepods as live feed organisms in marine larviculture. Aquaculture Research 37:756-772.

Evjemo, J. O., K. I. Reitan, and Y. Olsen. 2003. Copepods as live food organisms in the larval rearing of halibut larvae (Hippoglossus hippoglossus L.) with special emphasis on the nutritional value. Aquaculture 227:191-210.

FAO (Food and Agriculture Organization of the United Nations). 2008. The state of world fisheries and aquaculture: SOFIA 2008. FAO, Rome.

Folch, J., M. Lees, and G. H. Sloane-Stanley. 1957. A simple method for the isolation and purification of total lipids from animal tissues. Journal of Biological Chemistry 226:497-507.

Guangxing, L., and X. Donghui. 2009. Effects of calanoid copepod Schmackeria poplesia as a live food on the growth, survival and fatty acid composition of larvae and juveniles of Japanese flounder, Paralichthys olivaceus. Journal of Ocean University of China 8:359-365.

Hamre, K., A. Srivastava, I. Ronnestad, A. Mangor-Jensen, and J. Stoss. 2008. Several micronutrients in the rotifer Brachionus sp. may not fulfill the nutritional requirement of marine fish larvae. Aquaculture Nutrition 14:51-60.

Hunter, J. 1981. Feeding ecology and predation of marine fish larvae. Pages 33-77 in R. Lasker, editor. Marine fish larvae: morphology, ecology, and relation to fisheries. University of Washington Press, Seattle.

Kraul, S., A. Nelson, K. Brittain, H. Ako, and A. Ogasawara. 1992. Evaluation of live feeds for larval and postlarval mahimahi Coryphaena hippurus. Journal of the World Aquaculture Society 23:299-307.

Lavens, P., and P. Sorgeloos. 1999. Manual on the production and use of live food for aquaculture. FAO (Food and Agriculture Organization of the United Nations) Fisheries Technical Paper 361.

Lee, C.-S., P. J. O'Bryen, and N. H. Marcus. 2005. Copepods in aquaculture. Blackwell Scientific Publications, Ames, Iowa.

Lee, K. W., H. G. Park, S.-M. Lee, and H.-K. Kang. 2006. Effects of diet on the growth of the brackish water cyclopoid copepod Paracyclopina nana Smirnov. Aquaculture 256:346-353.

Leis, J. M. 1991. The pelagic stage of reef fishes. Pages 183-230 in P. F. Sale, editor. The ecology of fishes on coral reefs. Academic Press, San Diego, California.

Marcus, N. H., and J. A. Wilcox. 2007. A guide to the meso-scale production of the copepod Acartia tonsa. Florida Sea Grant College Program, Gainesville.

McKinnon, A. D., S. Duggan, P. D. Nichols, M. A. Rimmer, G. Semmens, and B. Robino. 2003. The potential of tropical paracalanid copepods as live feeds in aquaculture. Aquaculture 223:89-106.
Muller, R. G., K. Tisdel, and M. D. Murphy. 2002. The 2002 update of the stock assessment of Florida pompano (Trachinotus carolinus). Florida Fish and Wildlife Conservation Commission, Florida Marine Research Institute, St. Petersburg.

Ogle, J. T., J. T. Lemus, L. C. Nicholson, D. N. Barnes, and J. M. Lotz. 2005. Characterization of an extensive zooplankton culture system coupled with intensive larval rearing of red snapper Lutjanus campechanus. Pages 225-244 in C.-S. Lee, P. J. O'Bryen, and N. H. Marcus, editors. Copepods in aquaculture. Blackwell Scientific Publications, Ames, Iowa.

Ohs, C. L., K. A. Chang, S. W. Grabe, M. A. DiMaggio, and E. Stenn. 2010a. Evaluation of dietary microalgae for culture of the calanoid copepod Pseudodiaptomus pelagicus. Aquaculture 307:225-232.

Ohs, C. L., A. L. Rhyne, S. W. Grabe, M. A. DiMaggio, and Stenn E.. 2010 b. Effects of salinity on reproduction and survival of the calanoid copepod Pseudodiaptomous pelagicus. Aquaculture 307:219-224.

Olivotto, I. F., Capriotti, I. Buttino, A. M. Avella, V. Vitiello, F. Maradonna, and O. Carnevali. 2008. The use of harpacticoid copepods as live prey for Amphiprion clarkii larviculture: effects of larval survival and growth. Aquaculture 274:347-352.

Østergaard, P., P. Munk, and V. Janekarn. 2005. Contrasting feeding patterns among species of fish larvae from the tropical Andaman Sea. Marine Biology 146:595-606.

Payne, M. F., and R. J. Rippingale. 2001. Intensive cultivation of the calanoid copepod Gladioferens imparipes. Aquaculture 201:329-342.

Payne, M. F., R. J. Rippingale, and J. J. Cleary. 2001. Cultured copepods as food for West Australian dhufish (Glaucosoma hebraicum) and pink snapper (Pagrus auratus) larvae. Aquaculture 194:137-150.

Rainuzzo, J. R., K. I. Reitan, and Y. Olsen. 1997. The significance of lipids at early stages of marine fish: a review. Aquaculture 155:103-115.

Rajkumar, M., and K. P. Kumaraguru vasagam. 2006. Suitability of the copepod, Acartia clausi as a live feed for seabass larvae (Lates calcarifer Bloch): compared to traditional live-food organisms with special emphasis on the nutritional value. Aquaculture 261:649-658.

Reitan, K. I., J. R. Rainuzzo, G. Oie, and Y. Olsen. 1997. A review of the nutritional effects of algae in marine fish larvae. Aquaculture 155: 207-221.

Rhyne, A. L., C. L. Ohs, and E. Stenn. 2009. Effects of temperature on reproduction and survival of the calanoid copepod Pseudodiaptomus pelagicus. Aquaculture 292:53-59.

Samprey, A., A. D. McKinnon, M. G. Meekan, and M. I. McCormick. 2007. Glimpse into guts: overview of the feeding of larvae of tropical shorefishes. Marine Ecology Progress Series 339:243-257.

Sargent, J., G. Bell, L. McEvoy, D. Tocher, and A. Estevez. 1999b. Recent developments in the essential fatty acid nutrition of fish. Aquaculture 177:191199.

Sargent, J., L. McEvoy, and J. G. Bell. 1997. Requirements, presentation and sources of polyunsaturated fatty acids in marine fish larval feeds. Aquaculture 155:117-127.

Sargent, J., L. McEvoy, A. Estevez, G. Bell, M. Bell, J. Henderson, and D. Tocher. 1999a. Lipid nutrition of marine fish during early development: current status and future directions. Aquaculture 179:217-219.

Shields, R. J., J. G. Bell, F. S. Luizi, B. Gara, N. R. Bromage, and J. R. Sargent. 1999. Natural copepods are superior to enriched Artemia nauplii for halibut larvae (Hippoglossus hippoglossus) in terms of survival, pigmentation and retinal morphology: relation to dietary essential fatty acids. Journal of Nutrition 129:1186-1194.

St. John, M. A., C. Clemmesen, T. Lund, and T. Koster. 2001. Diatom production in the marine environment: implications for larval fish growth and condition. ICES Journal of Marine Science 58:1106-1113.

Stottrup, J. G. 2000. The elusive copepods: their production and suitability in marine aquaculture. Aquaculture Research 31:703-711.

Stottrup, J. G. 2003. Production and nutritional value of copepods. Pages 145-205 in J. G. Stottrup and L. A. McEvoy, editors. Live feeds in marine aquaculture. Blackwell Scientific Publications, Oxford, UK. 
Stottrup, J. G., J. G. Bell, and J. R. Sargent. 1999. The fate of lipids during development and cold-storage of eggs in the laboratory-reared calanoid copepod, Acartia tonsa Dana, and in response to different algal diets. Aquaculture 176:257-269.

Stottrup, J. G., and J. Jensen. 1990. Influence of algal diet on feeding and egg-production of the calanoid copepod Acartia tonsa Dana. Journal of Experimental Marine Biology and Ecology 141:87-105.

Stottrup, J. G., and L. A. McEvoy. 2003. Live feeds in marine aquaculture. Blackwell Scientific Publications, Oxford, UK.

Stottrup, J. G., and N. H. Norsker. 1997. Production and use of copepods in marine fish larviculture. Aquaculture 155:231-247.

Toledo, J. D., M. S. Golez, M. Doi, and A. Ohno. 1999. Use of copepod nauplii during early feeding stage of grouper Epinephelus coioides. Fisheries Science 65:390-397.

van Der Meeren, T., R. E. Olsen, K. Hamre, and H. J. Fyhn. 2008. Biochemical composition of copepods for evaluation of feed quality in production of juvenile marine fish. Aquaculture 274:375-397.
Weirich, C. R., and K. L. Riley. 2005. Development of reproduction and larviculture protocols for the production of Florida pompano: a USDA and HBOI research initiative. International Sustainable Marine Fish Culture Conference and Workshop, Fort Pierce, Florida.

Weirich, C. R., and K. L. Riley. 2007. Volitional spawning of Florida pompano, Trachinotus carolinus, induced via administration of gonadotropin releasing hormone analogue (GnRHa). Journal of Applied Aquaculture 19:47-60.

Weirich, C. R., D. R. Groat, R. C. Reigh, E. J. Chesney, and R. F. Malone. 2006. Effect of feeding strategies on production characteristics and body composition of Florida pompano reared in marine recirculating systems. North American Journal of Aquaculture 68:330-338.

Wilcox, J. A., P. L. Tracy, and N. H. Marcus. 2006. Improving live feeds: effect of a mixed diet of copepod nauplii (Acartia tonsa) and rotifers on the survival and growth of first-feeding larvae of the southern flounder, Paralichthys lethostigma. Journal of the World Aquaculture Society $37: 113-120$. 